\title{
A Study on the External Communication Strategy of Martial Arts Culture
}

\author{
Zhiliang $\mathrm{Li}^{1}$ Zhuo $\mathrm{Li}^{2}{ }^{2 *}$ \\ ${ }^{1}$ Zhejiang International Studies University, Hangzhou, Zhejiang 310012, China \\ ${ }^{2}$ Zhejiang Technical Institute of Economics, Hangzhou, Zhejiang 310018, China \\ *Corresponding author.Email: 58815378@qq.com
}

\begin{abstract}
The study uses literature and logical analysis methods to deeply explore the martial arts culture as the crystallization of Chinese wisdom, which has moral, ethical, spiritual and self-cultivation connotations. Nowadays, martial arts culture plays an important role on interpreting traditional Chinese culture, public communication and becoming a new economic growth point of cultural industry. The study suggests that there are still problems existing in the current international communication of martial arts culture: first, the cultural awareness between Chinese culture and Western culture is insufficient; second, the ways of external communication lack compatibility, universality and high-end talents; third, the conservatism is pervasive; fourth, martial arts culture lacks industrial amalgamation. Suggestions of spreading martial arts culture through films and teaching, breaking traditional conservatism by training martial arts talents through higher education, and enhancing the influence of martial arts culture by integrating culture and industry are put forward. The author hopes that the suggestions above can help to meet the spiritual and cultural needs of people in all countries, so as to promote Chinese martial arts culture to truly "go out".
\end{abstract}

Keywords: Martial arts culture, External communication, Communication strategy.

\section{INTRODUCTION}

With the development of globalization, the martial arts as an excellent traditional Chinese culture, not only contains the spiritual will of the Chinese nation, but also widely spreads and blends in the international society with the change of the times. The international spread of martial arts carries the international concept of China, which is one of the main ways of communication in the context of world culture. Culture is the lifeblood of a country and the foundation of the nation, and we should encourage to spread traditional culture with Chinese characteristics. The culture of Chinese civilization is a "booster" for the development of modern sports, and a "fusion agent" for the harmonious development of the countries. Therefore, it is necessary to show the most spiritual, essential, representative and valuable treasures of Chinese excellent traditional culture to the world, which is very conducive to promote China's international status in all aspects [1].
Culture is created in the process of human development, and seeking cultural diversity is to meet the needs of human beings [2]. Martial arts culture has been closely related to people's lives from ancient times. People made stone knives and bone forks for self-sufficiency in the original period, met the needs of the rulers in the bronze period, and now meet the needs of fitness and entertainment through martial arts activities. As it were, the development of martial arts is closely related to the formation and development of Chinese five thousand years' culture. So how can China let the world understand its history and traditions through Chinese martial arts culture? And in what ways and what channels, can China communicates its traditional culture with other countries and spreads traditional sports culture as well, which is in order to meet the spiritual needs of people around the world and thus let the Chinese martial arts culture be disseminated. 


\section{THE CONNOTATION AND COMMUNICATION VALUE OF MARTIAL ARTS CULTURE}

Martial arts, also called wushu, are not the confrontation with society, people and nature. Its original intention is to "stop violence with wushu". For example, it is said that "Wu, is to stop the war" in The Chronicle of Zuo. And Han History says "people prevent violence and stop fighting with wu". "Wu" in Chinese is the meaning of stop fighting and war, while "shu" represents skill. On the whole, Wushu is the skill and method for others to drop off violence. From ancient times till today, the art of attack and defense has run through the development of wushu. With the change of the times, the skill of wushu and the essence behind it has changed, that is the formation of Wushu culture system, which can be analyzed from four aspects:

The first point is the moral connotation of martial arts culture. The attack-and-defense characteristic is the essential characteristic of martial arts, and culture exists as its fundamental characteristic. The martial arts learners are marked by virtue from learning to actual combat. For example, in a martial arts action movie, if someone defeats the other, they will perform a fist salute with each other or pick up their clothes to cover the loser, which is to show their respect to rivals and their morality of martial arts. The morality of martial arts is the rules and norms that martial arts learners should observe together. Strictly speaking, it belongs to the ideological sphere. From the perspective of "law", the morality of martial arts belongs to "soft law", and there is no formal document of it. This also shows that the morality of Chinese martial arts is a key factor that makes martial arts culture accepted and recognized by people. Materialist dialectics believe all existence has its reason and historicity. In other words, the morality of martial arts has received social and human emotional recognition, so it has become a fundamental part for moral practice.

The second point is the ethical connotation of martial arts culture. The reason why China can retain the traditional culture for thousands of years mainly depends on the model of "seeking inheritance before development", which makes people unable to stay in the consciousness of "not forgetting their roots" psychologically [3]. Therefore, the Chinese cultural system is greatly influenced by traditional ethics, and many cultural carriers of inheritance and development are affected by this. So is the Chinese martial arts culture. It is full of conservative ideas and traditional sense. For example, when teaching Chinese martial arts, the inheritance of martial arts generally build on the master-apprentice relationship, and the master takes high status in apprentice's development. The master-apprentice relationship is nearly as important as parent-child relationship. In addition, there is an advice that the martial arts learners shouldn't have a second master, namely, the apprentice can only learn one kind of martial arts skill; in this way the successor can inherit both masters' thought and their skills, which greatly promotes the development of Chinese martial arts and the formation of martial arts schools. But the development of things is changeable, and there are two sides in the process of development. This conservative way of inheriting has caused the disappearance of martial arts fist and even the martial arts schools.

The third point is the spiritual connotation of martial arts culture. With the change of productive forces and production relations, people's demand for spiritual culture is constantly increasing. As a carrier of traditional culture, martial arts also give people other meanings except wrestle in the process of inheritance and development - spiritual connotation. Some scholars believe that people rationally organize and practice various cultures and successfully reflect them in all aspects of social development [4]. Similarly, martial arts culture is also an internal image formed by people in the stable social life. The Chinese martial arts culture system is a multi-faceted, but the most important one is its cultural spiritual aspect. Mr. Zhang Dainian considers that the basic spirit of Chinese traditional cultural element carrier is "self-struggle and noble-generous mind", and it is exactly the spiritual connotation of Chinese martial arts culture. In recent years, the research on the spiritual aspect of martial arts culture has been much deeper, and the harmonious cultural thought has also been blended in it. First of all, the "self-struggle" of the spiritual connotation of martial arts refers to that the martial arts learners practice hard and constantly, and then become powerful. This powerfulness doesn't mean making others scared in an oppressed way. The "self-struggle" of martial arts is more beneficial for people to live in harmony. Secondly, the "noble-generous mind" of the spiritual connotation of martial arts, emphasizes "De" and "Zai". "De" is the morality of martial arts and it is the most fundamental "soft law" of martial arts culture, and it has been the core recognized by more and more people for a long time. The martial 
arts learners continue to improve their skills and morality, which is a key way to inherit and spread traditional Chinese culture. "Zai" is to carry all things with broad mind, and improve the whole social morals through the skills and connotation of martial arts. It is also the very foundation for the development of a harmonious society. Otherwise the spiritual and cultural aspect of Chinese martial arts will become "virtual culture" with utopian color.

The fourth point is the self-cultivation connotation of martial arts culture. Chinese martial arts have always relied on traditional cultures such as "traditional philosophy, traditional medicine, and various doctrines" to form an independent system. As time passes, it has formed a harmonious relationship among human, nature and society. Therefore, Chinese martial arts are the traditional sports with both internal and external training. Martial arts not only exercise the body, but also helps people to enhance their self-cultivation. This means that martial arts have shifted from a fighting skill into an integrated skill of entertainment, bodybuilding and self-defense, so as to achieve the goal of getting refined internally and externally.

The spread of Chinese martial arts is a deep cross-cultural exploration. Overall, there are three values of achieving external communication through the spread of martial arts culture: First, interpret Chinese traditional culture in detail on the basis of martial arts culture. Martial arts culture is contagious. China is so big, and the cultural types in different parts of China have turn into today's martial arts culture system. We can achieve cultural diplomacy and wushu diplomacy through continuous culture export. Second, seek national fusion by taking martial arts culture as the starting point. With a view of pursuing health, we try to make foreign friends think that practicing martial arts is good, so as to reach the intersection of mind and satisfy their curiosity about Chinese martial arts culture. And finally it will form an atmosphere of learning from each other and living in harmony. Third, introduce the Chinese traditional cultural to the outside world with the help of martial arts culture. The Chinese cultural industry develops slowly, and it is not fully developed and lacks of tension. Only when the Chinese martial arts cultural industry of film, game and performance have been developed, can we vigorously make high-tech research on martial arts culture, and hope it to become a new growth point.

\section{THE CURRENT SITUATION AND PREDICAMENT ON THE SPREAD OF MARTIAL ARTS CULTURE}

\subsection{There Are Differences Between Chinese Culture and Western Culture in the Process of External Communication}

Chinese martial arts culture is considered as the crystallization of excellent traditional cultural wisdom, because it is a reflection of Chinese traditional medicine, philosophy, ideology, values of governors in different periods and logical ways of disseminators. More importantly, the martial arts culture system is affected by all aspects of society, and its unique parts of moral principles and whole care also affect the external communication. The theories of Five Elements, Eight Diagrams and Yin and Yang contained in martial arts can't be checked up in western culture, then get integrated and spread. The way of spreading Chinese martial arts is to teach it through words and deeds. The boxing theories or routine techniques are taught with more oral expression and less literal expression. Therefore, the biggest difficulty of spreading martial arts is to translate and express its original ideas in words. However, the thinking ways and values of western culture are relatively open, and any technique is implemented into scientific data and words. What's more, the ethics ideology won't be a hinder in the development of western culture. All these differences make martial arts not spread completely.

\subsection{The Spread of Martial Arts Culture Lacks Compatibility and Universality}

Chinese martial arts culture has always been on the way of "going out", but as a carrier of Chinese excellent traditional culture, it hasn't formed a perfect and independent system. At present, there are three ways of spreading Chinese martial arts culture, including Chinese Kung Fu movies, one of the Confucius Institute courses, and sports diplomacy through folk martial arts education. This form of spreading let the spreader form a thinking of "martial arts master or king fighter", "conceptual arts master education" and "competitive martial arts", which makes martial arts disconnected from its essence in certain extent. Therefore, it calls for external communication through an integrated way of from tradition to skill, from skill to performance, from performance to education, and from education 
to culture, which makes Chinese martial arts culture more suitable for the international strategy of "going out".

\subsection{The External of Martial Arts Culture Is Extremely Short of High-end Talents}

Talents are the cornerstone of nations, society and cultural communication. Cultivating highquality martial arts talents is the responsibility of Chinese martial arts and external communication of Chinese traditional culture. At present, the comprehensive quality of the spreader of Chinese martial arts needs to be improved. For example: The teaching method of Chinese martial arts based on body movements which should be mastered by spreaders. But the boxing theory and connotation can't be expressed simply through body movements, and it needs to be described with language. At the same time, martial arts must also be integrated with the relevant theories of modern sports, so that it will be in line with the local people's way of thinking, national conditions, and national characters when spreading. Although in recent years, martial arts students in various professional sports colleges and comprehensive colleges have strengthened the study of language, martial arts theories, and sports-related theories, but the quality of training is not very satisfactory. Of course, highend talents do not come overnight. They need take on the task of spreading martial arts after a longterm learning, training and practice. We should spare no effort to spread Chinese martial arts culture and traditional culture, and then to meet the actual needs of international communication.

\subsection{The "Conservatism" Is Widespread in the Spread of Martial Arts}

"Conservatism" is not a stranger to Chinese martial arts culture, which is also an inevitable phenomenon in the process of cultural inheritance, especially for comprehensive, syncretic and receptive Chinese traditional culture. From "soil foreign sports disputes" to "attacked by western sports" and then to "learn liberalism from former Soviet Union", Chinese traditional culture has been under constant attack. In order to protect and preserve traditional culture better, continuous reform and innovation have been adopted to adapt the world, which is actually a conservative transformation of culture. The martial arts culture is spread by this so-called "transformation" all the time, which is also closely related to the cultural background [5]. This national patriotism is far from the original intention of true patriotism, which greatly prevents the world to understand the martial arts culture. Therefore, Chinese traditional sports culture needs to assimilate the martial arts culture, use the martial arts culture to accept it, and spread its origins and spirits as a whole, so as to stabilize the position of Chinese culture as a cultural power in the world.

\subsection{The Martial Arts Culture Is in Lack of "Industrial Integration" in the Process of International Communication}

The cultural industry started in the early twentieth century. IT aims at people's spiritual and cultural needs, convert cultural creation to productivity, and finally provided people with products. Martial arts culture is a multi-level cultural system, which can form a unique cultural industry chain with the help of modern industrial technology [6]. Since then, the mode of external communication with a combination of technology, culture and industry has been formed. Now, although the martial arts culture has a certain industrial structure for external communication, it is limited to the martial arts education industry and the martial arts film industry, and there is no real integration. Therefore, in order to make a benign external communication of martial arts, it should adapt to the requirements of the age, and develop cultural industry with the economy to promote the formation of international martial arts industry, including film and television, education, book publishing, tourism products with martial arts cultural background, etc.

\section{STRATEGIES FOR THE INTERNATIONAL COMMUNICATION OF MARTIAL ARTS CULTURE}

\subsection{Focusing on Movies and Teaching As Well}

\subsubsection{At the Level of Communication Content, Martial Arts Movies Are Closely Linked to the Horizontal and Vertical Dimensions}

From Jackie Chan, Jet Li, Jason Wu to Sammo Hung, Chinese martial arts action movies have attracted much attention. For example, Wolf Warriors 2 directed and acted by Jason $\mathrm{Wu}$ has 
become the top 100 box office in the world. It gives some room for the improvement of spreading Chinese martial arts and let traditional culture have a say in external communication to a large extent [8]. Therefore, Chinese martial arts culture can rely on its inbuilt advantage and use multimedia technology to form a film mode for external communication. The path of martial arts action film also needs constantly exploration, and each film has its own focus point, and the same is true of Chinese martial arts action movies. It should follow the horizontal and vertical dimensions to make deep and wide spread.

First, we should pursue people-centered cultural creation, and express martial arts culture theme on the form of martial arts. This kind of film and television works must be closely related to the needs of people. These works can fully display the image of Chinese people and Chinese martial arts. Once they become products, they are regarded as works to just show the "shape" of traditional Chinese culture by foreign media. For example, Buddies in India starring Wang Baoqiang and Yue Yunpeng is a comedy, but it doesn't deviate from the Chinese martial arts of monkey boxing, so is the film Duo Bao Da Shi under China-Greece cooperation. This has also promoted the friendship with the people in other countries. At the same time, private enterprises have accomplished crossnational and cross-cultural exchange and cooperation with the help of cultural dividend, thereby enhancing the status of China's soft power.

Second, we can express martial arts culture theme through the connotation of martial arts focusing on consciousness. This type of film is mainly made at the level of national spirit, and to discover the power of Chinese martial arts in video form in its process of development and construction. For example, the movie Dragon Blade filmed in 2015, starring Jackie Chan. During the filming, the cast and crew were warmly welcomed by the people of neighboring countries. More importantly, the offensive and defensive skill of Chinese sword is fully displayed in this film. This is an important way to excavate the deep level of Chinese culture. As a carrier of cultural transmission, trans-national or trans-regional filming has become a normal phenomenon in the film industry, and it promotes the communication of economy, culture and education among countries [8]. The Chinese martial arts is indispensable element in exploring the different functions of culture. Therefore, with the combination of the horizontal and vertical dimensions, government guides the enterprises and civil organizations to enhance communication, which is helpful to the spread the martial arts culture.

\subsubsection{Confucius Institute-based Education and Making Different Teachings}

As one of the most important bases for spreading Chinese traditional culture, Confucius Institute has played a key role in the international promotion of Chinese language, Chinese medicine theory, and martial arts. At present, Confucius Institute has become the highlight of national culture communication in the new era. It has made countries and nations closer to a large extent, greatly reduced their contradictions, and inspired people's spiritual and cultural emotions [9]. Chinese martial arts is also one of the most important courses of spreading traditional culture in Confucius Institute. By the end of 2016, nearly onethird of the 512 Confucius Institutes in the world have offered martial arts courses (Tai Chi) [10]. However, due to policy and condition reasons, the quality of teachers differs widely, the teachers flow frequently and teaching content lacks pertinence [11]. It is believed that there are two main reasons: First, the state doesn't pay enough attention to the carrier of martial arts, and the relevant policies are not implemented. So it is important to strengthen policy support in the external promotion of martial arts in the future. More importantly, teaching content lacks pertinence, and is even assimilated by local culture. The martial arts is the crystallization of Chinese wisdom, and the teaching of it should always adhere to Chinese traditional culture as the core. In the process of external communication, it must be taught according to age, physiological structure, psychology and people's knowledge of martial arts. In other words, the teachers need to know the level and cognition degree of the learners, and then make different teaching to promote the quality of martial arts culture spread.

\subsection{Cultivating Martial Arts Talents Through Higher Education}

Disseminators have a responsibility to spread the excellent Chinese traditional culture. At present, there are two types of teachers or coaches for martial arts spread: one is excellent teachers in domestic universities or martial arts majors who need short-term internship; the other is learners from folk martial arts school. They teach martial arts in local martial club and make a charge. It seems that the strength of teachers is not weak. 
However, for the long-term external communication of martial arts culture, there are general phenomena of low technological level, shallow cognition of martial arts culture or even Chinese traditional culture, and extremely lacking professional language. As we all know, talent is the core force that helps Chinese traditional culture go out, and it is also important for foreign friends to understand traditional Chinese culture [12]. Therefore, the cultivation of martial arts talents for external communication should be based on higher education and supplemented by folk training, but the whole training system should focus on three points: First, strengthen the education of traditional Chinese culture. In recent years, Chinese martial arts have become an important means of sports diplomacy, and martial arts learners have become "splendid pearls", but they do not have a thorough understanding of the deep traditional connotation of martial arts culture, resulting in the lack of spiritual culture. So it is necessary to integrate traditional culture and martial arts culture into education, and establish a perfect assessment system of martial arts culture education, so as to ensure a good spread of Chinese martial arts culture. Second, apply foreign language to the training program of martial arts talent. Language proficiency can not only reflect the comprehensive quality of martial arts learners, but also show learners' knowledge reserve and ability. The martial arts teachers should have a deep understanding of national customs and differences between Chinese culture and local culture, and know how to spread the martial arts in the teaching process. Third, translate professional terms of martial arts. Translation is a medium for spreading Chinese culture. In order to introduce the martial arts culture to the world truly and completely, the first task is to translate professional terms. Although there are some books about martial arts translation, the martial arts is diversified, and universities should strengthen the cultivation of translation talents. Professor Zhou Mingwei of Fudan University believes that "translation is a key to train high-end talents, otherwise it will seriously affect the international communication of Chinese culture" [13]. Generally speaking, in order to spread the martial arts culture, we must rely on traditional culture and social practice, and put it into practice, namely, strengthen the cultivation of traditional culture, language and professional martial arts translation.

\subsection{Breaking the Traditional Conservatism}

Conservatism is a symbolic phenomenon of China's intangible heritage. It is consciousness of self-protection formed under western cultural shock and it is put into practice by "traditionalists". However, with the changes of the times, these theories and practices haven't been really popularized. Instead they have been assimilated by new culture and entered a new relatively stable stage [15]. China is one of the ancient civilizations in the world, with a history of more than 5,000 years, and martial arts has matured under the transition of civilization. In the late Qing dynasty and early Republic of China, there was a conflict between traditional martial arts and competitive martial arts, and the martial arts fist is taught from only for apprentice to all people. This is a typical feature of traditional Chinese conservatism. The proposal of "Martial arts originates from China, but belongs to the world" breaks the traditional conservatism, which fully proves the inclusiveness and acceptance of Chinese culture, and shows that China can make peace with other countries in the world. Therefore, the spread of Chinese martial arts culture should embrace the world and create a unique communication system of martial arts culture.

\subsection{Integrating Culture and Industry to Improve the Influence of Martial Arts Culture}

The cultural industry is a new theme since the market economy was proposed, and culture-related industries have also made a lot of theoretical and practical research. Martial arts culture industry should inherit and develop traditional Chinese culture, highlight cultural characteristics. As the cultural soft power becomes increasingly important, it is a rare opportunity to develop the martial arts culture industry. The ways to improve the influence of martial arts culture are as the following three aspects: First, improve the industrial marketing model. The marketing model is simply to use different way to open up the market, so as to obtain higher profits and value. This is especially true for the martial arts industry marketing model, which should be integrated with commodities, tourism, film and television, etc. [15], use media technology to expand production, and increase profits and improve cultural influence as well. Second, establish a unique brand of martial arts industry to meet the needs of different groups in the new era, such as holding various martial arts competitions, 
developing martial arts education industry and raising the audience ratings and approval degree of martial arts programs and education [16]. Third, train professionals of the martial arts industry and establish a mechanism for two-way communication with society and abroad. The martial arts learners must be responsible for the external communication of martial arts culture. College teachers should compile professional textbooks of martial arts cultural industry and build a targeted industrial practice platform. Eventually, a complete system of external communication system from education to talents and from brand to industry will be formed. All these can help Chinese martial arts culture to win over its own position, and show the beauty of Chinese traditional culture to the world.

\section{CONCLUSION}

The Chinese martial arts is indispensable element in exploring the different functions of culture. Therefore, with the combination of the horizontal and vertical dimensions, government guides the enterprises and civil organizations to enhance communication, which is helpful to the spread the martial arts culture.

The martial arts is the crystallization of Chinese wisdom, and the teaching of it should always adhere to Chinese traditional culture as the core. In the process of external communication, it must be taught according to age, physiological structure, psychology and people's knowledge of martial arts. In other words, the teachers need to know the level and cognition degree of the learners, and then make different teaching to promote the quality of martial arts culture spread.

Generally speaking, in order to spread the martial arts culture, we must rely on traditional culture and social practice, and put it into practice, namely, strengthen the cultivation of traditional culture, language and professional martial arts translation.

Therefore, the spread of Chinese martial arts culture should embrace the world and create a unique communication system of martial arts culture.

Eventually, a complete system of external communication system from education to talents and from brand to industry will be formed. All these can help Chinese martial arts culture to win over its own position, and show the beauty of Chinese traditional culture to the world.

\section{AUTHORS' CONTRIBUTIONS}

The author Zhiliang Li has wrote this paper, the corresponding author Zhuo Li did the document literature search.

\section{REFERENCES}

[1] Zhang Hengjun: "Three Fulcrums for Increasing the Influence of Dissemination of Chinese Culture to the Outside World", "Outbound Communication", No. 7, 2019.

[2] Han Dongping: "Using Cultural Tool Theory to Understand Chinese Traditional Culture", "Henan Social Science", No. 3, 2008.

[3] Zhang Wenfu: "Inquiry into the Connotation of Wushu Culture", "Martial Arts Research", 2018, Volume 3, Issue 3.

[4] Zhao Zhongming: Sorcerer, Witchcraft, Secret Realm — Tracing of Chinese Witchcraft Culture. Kunming: Yunnan University Press, 1993 edition, p. 70.

[5] Wang Junqi: "Cultural Reflections on "Conservatism" from the Protection of Wushu Cultural Heritage", "Journal of Physical Education", 2008, Issue 2.

[6] Xie Mingyuan: "Research on the Mutual Promotion Mechanism of Wushu Cultural Industry and Soft Power under the New Economic Normal" "Chinese Wushu (Research)", Vol. 8, No. 4, 2019.

[7] Yin Jun, Kang Jianbing: "Innovative Thinking on the External Transmission of Chinese Films under the Background of the "Belt and Road"", "Journal of Southwest University for Nationalities (Humanities and Social Sciences Edition)", Vol. 40, Issue 5, 2019, 40.

[8] Cui Ying, Zhang Hanzhong: "A Brief Introduction to the Research on the Southeast Asian Film Industry from the Perspective of the "Belt and Road"", "China Film Market", Issue 8, 2017.

[9] Ma Suchuan, Yao Shengwang: "Research on the Cultural Exchange between China and Central Asia under the Background of the "Belt and Road" — Taking the Confucius Institute as an Example", Journal of the Party School of the CPC Jinan Municipal Committee, No. 3, 2019. 
[10] http://www.hanban.edu.cn/confuciousinstitute s/node_10961.html[EB/OL].

[11] Han Xiaoming, Hu Xiaofei: "Problems and Countermeasures of the Internationalization of Taijiquan-Taking the Confucius Institutes of Iceland, Norway and Cameroon as an Example", "Sports Culture Guide", No. 6, 2018.

[12] Bao Huaying: "My Opinions on the Cultivation of Intercultural Communication Talents - Talking from Sinologist An Lezhe", "External Communication", No. 3, 2019.

[13] Zhou Mingwei: "Building an International Translation Talent Team and Promoting Chinese Culture to Go Global", "Chinese Translation", Issue 5, 2014.

[14] Wang Wentao: "Analysis of Liberalism and Conservatism from the Perspective of Change", "Theory of Learning", No. 9, 2018.

[15] Song Bo, Liu Kai: "Exploration and Research on the Marketing Mode of Chinese Wushu Culture - Taking Shanxi Xingyiquan as an Example", "Chinese Wushu (Research)", Vol. 5, No. 1, 2016.

[16] Cao Jin: "Research on the Development of Wushu Industry in the New Era", "Journal of Huaibei Vocational and Technical College", 2018, Volume 17, Issue 517. 